\title{
The Simulation Method of Multi-Task Scheduling and Controlling in the Logistics Center
}

\author{
Zhao Wenjing and Cheng Guoquan
}

\begin{abstract}
The basic premise of this paper was to study the general principles of multi-task scheduling and controlling in the logistics center, specifically taking the AGV (Automated Guided Vehicle) as an example, setting the three-dimensional models of the equipments through MDT. This study established the relationships between the downstream equipments and the upstream equipments in Flexsim, taking the equipment layout into account and realizing the multi-task scheduling and controlling in the simulation model. As a result we got the visualization simulation models of a cigarette factory accessories distribution system and the simulation data which would support the further optimization process. This article provided a practical method which made a contribution in solving the problem that how to reproduce the reality system task scheduling and controlling strategy into the simulation models. In this way, it made a meaningful attempt of exploring the simulation method of tasks scheduling and controlling in the logistics center.
\end{abstract}

Index Terms-Logistics center, multi-task scheduling, simulation.

\section{INTRODUCTION}

Logistics center is the place or an organization which is engaged in logistics activities. In modern logistics, logistics center is no longer just having storage as its main function, but also covering picking, distribution, inspection, classification, processing, delivery and some other modern logistics functions. So its huge scale, highly informational automation, the requirements of efficiency, enormous throughput all add to the complexity of its management. As early as in 1969, Richard Muther had already put out the System Layout Planning Method which is known as the SLP method in his book Systematic Layout Planning [1]. On the other hand, JM Moore, as the representative of the facilities-planning scholars, systematically studied how to apply computer technologies for layout planning, and produced many layout programs written in programming languages which was called CAL method. Now in China there are a lot of scholars optimizing the system structure and logistics process of the logistics center through establishing the simulation system. So in the simulation test process, the problem that how to reproduce the real time system task scheduling and controlling strategy must be solved. In this way, the simulation system can be controlled and

Manuscript received April 24, 2013; revised June 10, 2013.

Zhao Wenjing is with studying in the Institute of Logistics Engineering, University of Science and Technology Beijing, Beijing, 100083, China for MS Degree. (e-mail: wjzhao1989@ hotmail.com).

Cheng Guoquan is with working in the Institute of Logistics Engineering, University of Science and Technology Beijing, Beijing , 100083, China as an Associate Professor (e-mail: cgq60@vip.sina.com). purposefully operated according to the reality. Therefore this study has selected the simulation method of the multi-tasks scheduling and controlling in the logistics center as the focus of research.

\section{The General Principles of the Multi-Tasks SCHEDULING AND CONTROLLING SIMULATION IN THE LOGISTICS CENTER}

According to their different location characteristics and operation mode, the logistics equipments can be divided into two kinds, one kind is called fixed equipment or resource equipment; the other one is called executive equipment or sharing equipment. The fixed equipment refers to the equipment whose position is relatively fixed and is responsible for storage, transport, processing, such as shelves, conveyor, stacker, processing center; while the executive equipment refers to the equipment whose position is not fixed, and can be moved in a certain region. This kind of equipment is usually responsible for loading and unloading, handling, such as AGV (Automated Guided Vehicle), forklift truck, manipulator, robot and so on[2].

The realization of the multi-tasks scheduling and controlling simulation means to reproduce the multi-tasks scheduling and controlling strategy of the real time system in the executive equipment which are working in the logistics center simulation system, so that the simulation system can simulate the real time operation condition in a controlled and purposeful manner. The main functions of the realization are, firstly, to simplify all of the various tasks and operations into controlling information, secondly transmit this information through messaging mechanism between different devices, in order to achieve the purpose of across-device control and coordination.

The specific contents of the tasks scheduling and controlling includes setting up the mathematical description of the tasks operation, generating the task command, generating, sending, managing and executing the controlling information, and scheduling vehicles in logistics center.

\section{A. Generate the Task Command}

Specifically, the generation of the task command is divided into three steps: 1) create the task sequence; 2) insert specific tasks into the task sequence; 3 )send the task sequence.

This paper puts forward the concept of unitized task. In this concept, all kinds of tasks in the logistics center can abstract into a sequence of standard operating tasks. So we can use basic operation and unitization task to describe the tasks of the equipment system in the logistics center according to this notion.

An ordered combination which consists of a certain 
number of unit operations can be seen as a task unit. Every task unit can be described as the following formula:

$T S=\{$ which equipment need this task, which equipment will accept this task, Pr(priority), Pm(preemption), Task1, Task $2, \ldots\}$

In this formula, the task is one kind of operating commands which ask the executive equipment to execute a single basic operation which include travel, load, unload, stay, wait, sending message and so on. The task command can be described as the following formula:

$$
\text { Task }=T f \text { (parameter } 1, \text { parameter } 2, \ldots)
$$

The task sequence is one kind of operating commands which ask the executive equipment to execute a series of basic operation systematically. It includes priority, preempt and one or more than one task command consisting in sequential order. The task sequence command can described as the following formula:

\section{Take Sequence $=\{\operatorname{Pr}$ (priority), Pm (preemption), Task1, Task2, Task3,..., Task $n\}$

The task sequence list is a queue of task sequences ordered by priority and preemption in the task buffer. The task sequence which has the first priority comes first. If two task sequences share the same priority, the one with higher preemption comes former. If two task sequences share the same priority and preemption, who comes early comes former.

\section{B. Scheduling Mechanism}

The scheduling mechanism is the way of how to generate, transmit, control and execute the task sequences and control information in the simulation model. It can be divided into three modes according to the difference of the subject who generate, send, receive, control and execute the task sequence 1) independent processing mode: the task sequence is sent by the executive equipment and is executed by itself. 2) asking for service mode: the service request is generated by any device, and the task request is sent by this device and received by the certain executive equipment which will not only receive but also control and execute the task. 3) centralized dispatching mode: the service requests are generated by some devices, and gathered by a task dispatcher. Then the task dispatcher will put all these service requests in order to make a task sequence list, and pick the suitable executive equipment to execute the tasks in accordance with the predefined task scheduling rules.

These three modes can be applied in the simulation flexibly. We can just choose the most convenient one or combine all these three modes in the modeling process.

\section{The Simulation Method of the Multi-Tasks SCHEDULING AND CONTROLLING OF THE AGV SYSTEM}

The AGV system is one of the core subsystems of the logistics center, which is also one of the most complex subsystems when setting the simulation model, especially for its traffic control and task scheduling [3]. Nowadays there still haven't got mature software that can easily realize the simulation of its traffic control and task scheduling [4]. So this chapter will discuss the simulation method of the multi-tasks scheduling and controlling of the AGV system.

\section{A. The Structure Modeling of $A G V$}

In reality, the AGVS generally constituted by the line (LINE), the vehicle (AGV), the working station (STATION), the charging station (HOME), and the control system (CS). The line is consisted by the node (NODE) and connection (CONNECTION). The AGV travels alone the line to complete the material handling work.

First we used the MDT software to make the three-dimensional model and output the 3DS file. Then we imported the file into the simulation system. The AGV shown in Fig. 1, for example, is divided into two parts to be shaped, one is the main body of the vehicle, and the other one is the fork-transplanting institution. Then we re-assembled these two parts together.

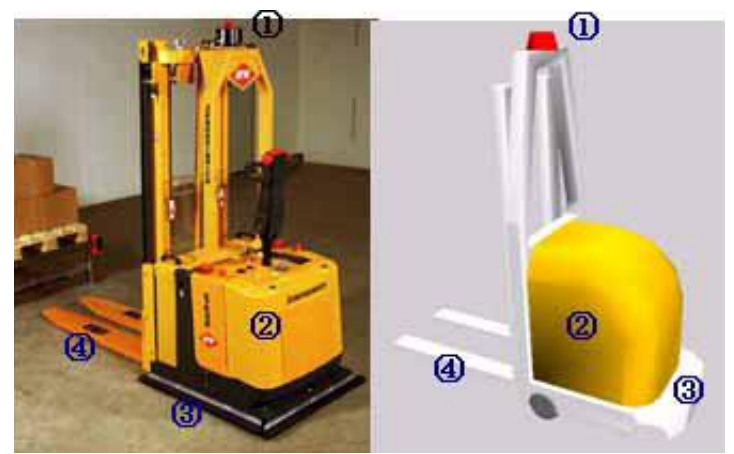

Fig. 1. The comparison of the real AGV and the simulation model

\section{B. The Simulation Modeling of Site}

According to the different operation made by AGV thereon, the sites can be separated into loading sites, unloading sites, loading and unloading sites, HOME and so on. On the other hand, according to the different method of being modeling, the sites can be separated into the active sites and the passive sites

The active site can send the request for service initially. It creates the task sequence itself according to its own needs and sends it to the task dispatcher. It can be described as the following formula:

$$
S=\{P, \text { Time }, \text { Task }\}
$$

In this formula, $P$ refers to a set of the positional parameters, Time refers to the rules of the time when the handling task starts, and Task refers to instruction of handling task. The active sites can be treated as processing center in the simulation process. The processing time which is the property of the processing center can simulate how long the handling service takes place. After the processing time, the processing center triggers the need of handling service and generates the task sequence, then sends the task sequence to the corresponding task dispatcher.

The passive site only provide or receive materials passively instead of generate request for handling service initially. These kind of site is relatively easy because it only has one parameter-position. On the other hand, it has various kinds of forms, and mainly functions as the connection with other subsystems, i.e., the buffer, the storage, the transfer or the termination. We can choose 'parts arrester', 'queue', 'conveyor', etc. to simulate it. 
Especially, Home is a special passive site in AGV system. It is a place where AGV can have a rest and being charged .It doesn't have operation demand, but if it is occupied by one AGV already, it will refuse other AGV.

\section{The Simulation Modeling of Circuit}

In the circuit simulation, if we connect two circuit nodes together, we can get a two-way line; if we cut off one of the direction, then it forms a one-way line. We have to set the appropriate distance between two AGVs in each section to avoid the conflict in the same circuit. In the intersection of the lines, we set the object of 'traffic light 'to make the AGVs that have arrived there to obey the 'First Come First Served (The one first comes can get across the intersection first)'rule. The limitation of the speed of each circuit and the deceleration point are set to control the speed of the AGV, especially in the turning.

\section{Generating the Standard Task Sequence}

As said at the beginning of this article, the tasks of the AGV just as other equipment also have to be unitized, and we also have to set up their mathematical expression. The main operation units of the AGV system include travel, load, unload, stay, wait and so on. The main task units of the AGV system include handling task, charging task (travel, stay, wait) and the free AGV getting back to Home task.

\section{E. The Simulative Realization of the Multi-Tasks Scheduling and Controlling of the AGVS}

1) The simulative realization of scheduling and controlling of the handling tasks:

Here we use the centralized dispatching mode which means that the service requests are generated by some devices, and gathered by a task dispatcher. Then the task dispatcher will put all these service requests in order to make a task sequence list, and pick the suitable executive equipment to execute the tasks in accordance with the predefined task scheduling rules.

2) The simulative realization of scheduling and controlling of the charging tasks:

Here we use the 'MTBF' of the external tools object provided by Flexsim to simulate the electric quality. We can add the record variables to it, and the record variables also can be set that if it achieves a certain value, it will send a message to trigger a mechanism. At the same time, we will use the same way to trigger the event of generating the charging task whose priority is 10 and preemption is 0 . Though the charging task will take precedence over all other tasks, it won't suspend the current task for its preemption is 0 . So the simulation will be the most consistent with the real system.

3) The simulative realization of scheduling and controlling of the free AGV getting back to Home task:

We will apply the independent processing mode in this part of simulation. Every time when the AVG get unloaded, it will judge if the AGV is free. If it is free, it will generate the instruction of getting back to home. Both of the priority and preemption of this instruction is 0 . So it can be interrupted by the tasks of accessories distribution and waste collection.

4) The simulative realization of the traffic control:

The traffic control will use the local principle and is managed by lines and nodes.
Unidirectional travel of AGV: The travel direction is determined by the type of the lines. There are two types of the lines one is bidirectional lines, the other one is unidirectional lines. People often use the unidirectional loop to avoid the traffic control to be too complicated. But around the loading and unloading station, it usually is the bidirectional lines.

Vehicle collision avoidance: We can set the attributes of line capacity and distance of vehicles to avoid the vehicle collision. At the same time, we set the object of 'traffic light' in the line intersection to control all the vehicles arrived there to obey the 'First Come First Served (The one first comes can get across the intersection first)'rule. So that we can make sure that for every moment there is one and only one vehicle get across the intersection.

Speed limitation: At the turning, the limitation of the speed of each circuit and the deceleration point are set to control the speed of the AGV.

\section{F. The AGVS Automated Simulation Modeling Prototype System Development:}

Firstly, we need to prepare a standard electronic map mad by CAD. Secondly, we write the program module which is called the image-transforming program by VB. It can provide the functions as below: 1) reads the related images drawn by $\mathrm{CAD}$, and transforms the image information into the digital information which will then be saved into the scheme database. 2) creates the standard scheme database where the digital information can be saved and controlled in a standard format by ACCESS . 3) sets up the automated simulation modeling program module which can transform the information in the database into the information of the simulation model. 4) displays the three-dimensional view of the simulation model on the simulation modeling window provided by Flexsim .Thirdly, we improve and run the simulation model [5]-[7]. The simulation modeling prototype will be presented in the next chapter.

\section{A REAl Simulation EXample of One Cigarette LOGISTICS CENTER}

There is a cigarette factory whose annual output of the finished cigarette can be 100 million boxes. The production line in the main plant includes 24 sets of the rolling, joining and packaging unit, 12 sets of the filter tip forming unit and 9 sets of the binning and sealing unit. Besides, the main plant is a two-tier structure. The AS/RS for the accessories, the AS/RS for finished product, the laser-guided AGV system, the related finished product conveying, and the sorting system consist the whole cigarette integrated manufacturing system controlled by computers. Particularly, the AS/RS for the accessories with the total capacity of 5120 has 4 roadways; the stock-in system which consists of the forklift trucks and the conveyors is on the first floor while the stock-out system which consists of the conveyors for the roadway, the shuttles and the platform is on the second floor; the accessories distribution system is consisted of the laser-guided AGV system.

\section{A. The Establishment of the Simulation Model of the Core Subsystem}

Generally speaking, the simulation modeling of the 
logistics equipment includes three steps: structure modeling, behavior realization and movement realization. The FLEXSIM support the secondary development and we can use the OpenGL to realize the visualized modeling. We can realize the parameterization of the models easily in this method, and it only takes few resources. All of the structural parameters, performance parameters and behavior, movement, processing logic of the parametric models which are set based on the OOT (Object-Oriented Technology) are integrated and encapsulated. These virtual entities are corresponding with the logistics equipment in the real system one-to-one [8]-[10].

This paper makes the full use of the concept of class and inheritance. All of the simulation models of the equipment we set before are used to compose each subsystem, just as the parts of a machine. The core subsystems of the logistics center include the storage system, the sorting system, the conveyor system, the handling system and the automatic classification system. All are shown in the Fig. 2.

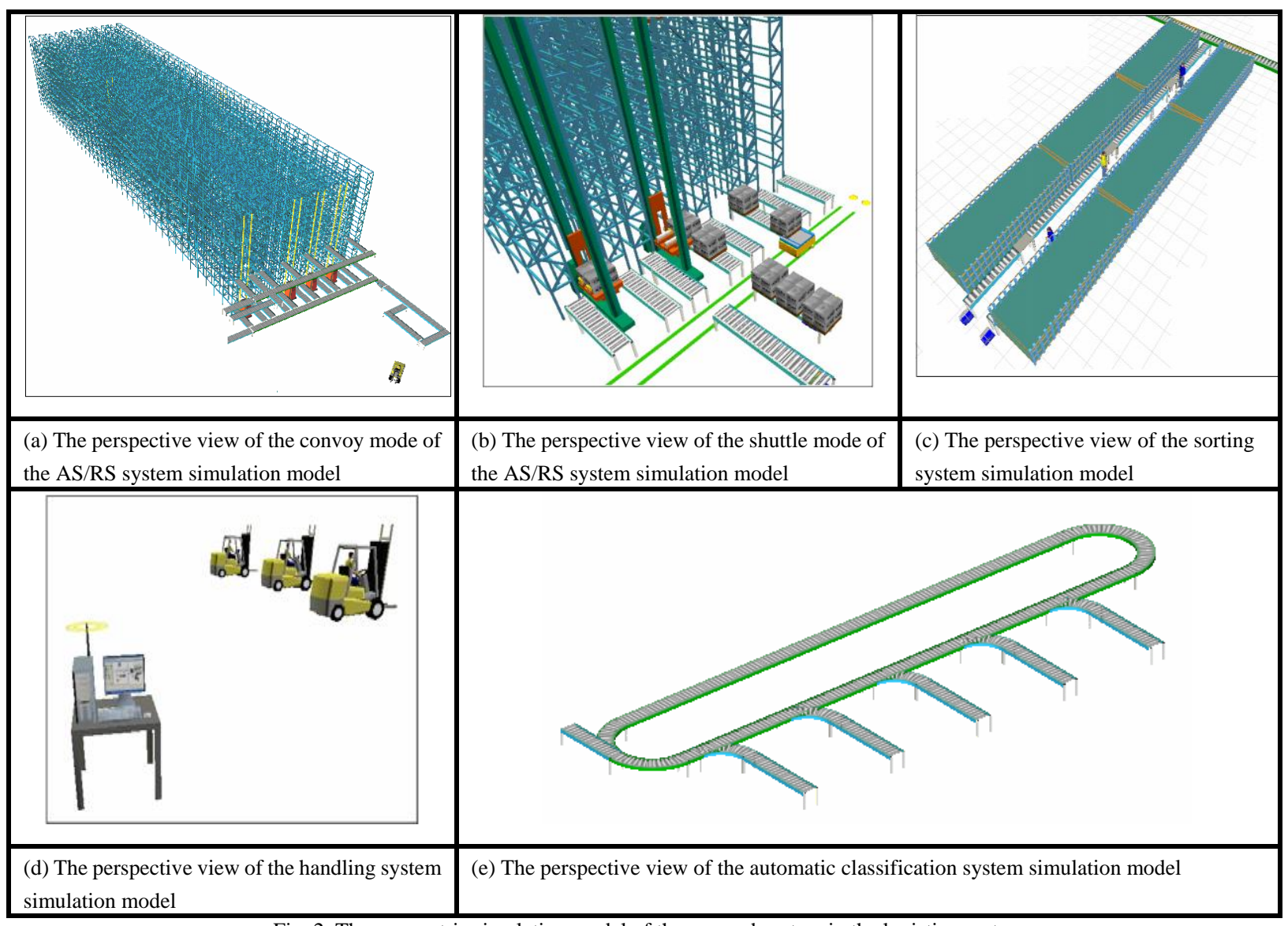

Fig. 2. The parametric simulation model of the core subsystem in the logistics center

\section{B. The Establishment of the Simulation Model of This Real Cigarette Logistics Center}

This cigarette logistics center includes two core subsystems: the AS/RS system and the AGV handling system. The automatic accessories distribution system which is set in the method described above is shown in Fig. 3 and Fig. 4.

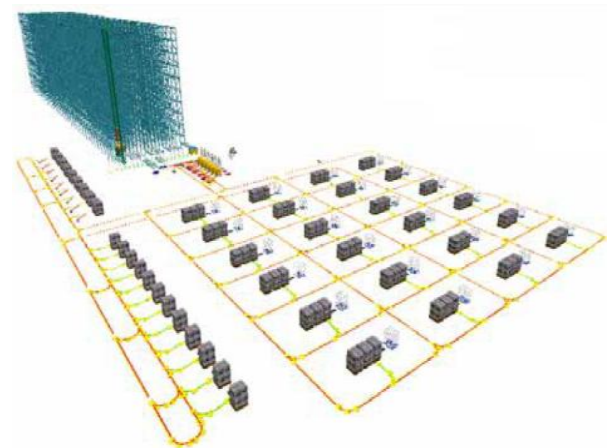

Fig. 3. The panorama of the simulation model

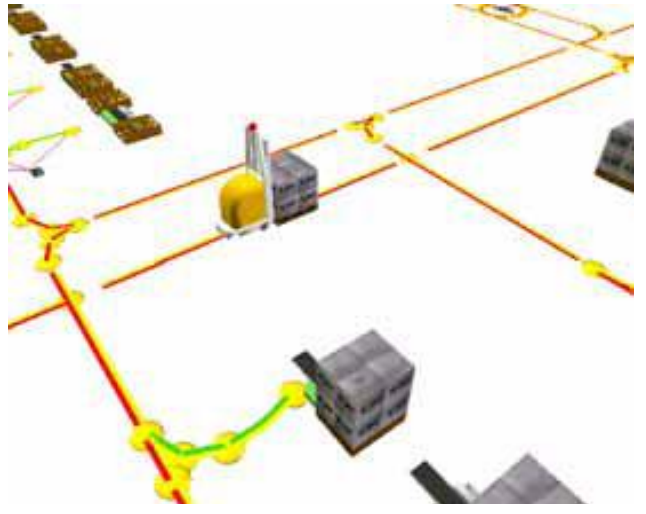

Fig. 4. Detail view_— the working AGV

We set the simulation time as 16 hours (57600s) and take the initialization time which is two hours (7200s) into account, the whole time is up to 18 hours (64800s). It observes and records the statistical data after 2 hours from the start, runs each of the programs for five times and takes the average of the statistical data. 
TABLE I: THE SIMULATION RESUlTS OF THE AGV SYSTEM IN DifFERENT PROGRAM

\begin{tabular}{|c|c|c|c|c|c|c|c|c|}
\hline \multicolumn{9}{|c|}{ program1:3 AGVs } \\
\hline Item & $\begin{array}{l}\text { The number of } \\
\text { execution }\end{array}$ & The idle rate & $\begin{array}{l}\text { The charging } \\
\text { time }\end{array}$ & $\begin{array}{l}\text { The unloading } \\
\text { walking time }\end{array}$ & $\begin{array}{l}\text { The loading } \\
\text { walking time }\end{array}$ & $\begin{array}{l}\text { The loading } \\
\text { time }\end{array}$ & $\begin{array}{l}\text { The unloading } \\
\text { time }\end{array}$ & $\begin{array}{l}\text { The total } \\
\text { load rate }\end{array}$ \\
\hline AGV1 & 202 & $7.16 \%$ & $6.00 \%$ & $15.73 \%$ & $54.83 \%$ & $8.15 \%$ & $8.13 \%$ & $92.84 \%$ \\
\hline $\mathrm{AGV} 2$ & 197 & $8.71 \%$ & $5.94 \%$ & $15.10 \%$ & $54.36 \%$ & $7.95 \%$ & $7.95 \%$ & $91.29 \%$ \\
\hline AGV3 & 199 & $8.44 \%$ & $7.04 \%$ & $14.96 \%$ & $53.49 \%$ & $8.05 \%$ & $8.03 \%$ & $91.56 \%$ \\
\hline average & $598($ total $)$ & $8.10 \%$ & $6.33 \%$ & $15.27 \%$ & $54.22 \%$ & $8.05 \%$ & $8.03 \%$ & $91.90 \%$ \\
\hline \multicolumn{9}{|c|}{ Program2:4 AGVs } \\
\hline Item & $\begin{array}{l}\text { The number of } \\
\text { execution }\end{array}$ & The idle rate & $\begin{array}{l}\text { The charging } \\
\text { time }\end{array}$ & $\begin{array}{l}\text { The unloading } \\
\text { walking time }\end{array}$ & $\begin{array}{l}\text { The loading } \\
\text { walking time }\end{array}$ & $\begin{array}{l}\text { The loading } \\
\text { time }\end{array}$ & $\begin{array}{l}\text { The unloading } \\
\text { time }\end{array}$ & $\begin{array}{l}\text { The total } \\
\text { load rate }\end{array}$ \\
\hline AGV1 & 178 & $20.16 \%$ & $6.59 \%$ & $13.13 \%$ & $46.28 \%$ & $6.92 \%$ & $6.92 \%$ & $79.84 \%$ \\
\hline AGV2 & 165 & $22.91 \%$ & $7.50 \%$ & $12.93 \%$ & $43.83 \%$ & $6.41 \%$ & $6.41 \%$ & $77.09 \%$ \\
\hline AGV3 & 152 & $24.67 \%$ & $7.24 \%$ & $13.28 \%$ & $42.23 \%$ & $6.29 \%$ & $6.29 \%$ & $75.33 \%$ \\
\hline AGV4 & 159 & $26.26 \%$ & $7.82 \%$ & $12.31 \%$ & $41.36 \%$ & $6.13 \%$ & $6.13 \%$ & $73.74 \%$ \\
\hline average & $654($ total $)$ & $23.50 \%$ & $7.29 \%$ & $12.91 \%$ & $43.42 \%$ & $6.44 \%$ & $6.44 \%$ & $76.50 \%$ \\
\hline \multicolumn{9}{|c|}{ Program3:5 AGVs } \\
\hline Item & $\begin{array}{l}\text { The number of } \\
\text { execution }\end{array}$ & The idle rate & $\begin{array}{l}\text { The charging } \\
\text { time }\end{array}$ & $\begin{array}{l}\text { The unloading } \\
\text { walking time }\end{array}$ & $\begin{array}{l}\text { The loading } \\
\text { walking time }\end{array}$ & $\begin{array}{l}\text { The loading } \\
\text { time }\end{array}$ & $\begin{array}{l}\text { The unloading } \\
\text { time }\end{array}$ & $\begin{array}{l}\text { The total } \\
\text { load rate }\end{array}$ \\
\hline AGV1 & 141 & $29.70 \%$ & $8.06 \%$ & $12.32 \%$ & $38.53 \%$ & $5.71 \%$ & $5.69 \%$ & $70.30 \%$ \\
\hline AGV2 & 139 & $30.14 \%$ & $8.69 \%$ & $12.58 \%$ & $37.45 \%$ & $5.57 \%$ & $5.57 \%$ & $69.86 \%$ \\
\hline AGV3 & 136 & $32.59 \%$ & $8.02 \%$ & $12.09 \%$ & $36.43 \%$ & $5.45 \%$ & $5.43 \%$ & $67.41 \%$ \\
\hline AGV4 & 126 & $36.40 \%$ & $9.12 \%$ & $10.66 \%$ & $33.79 \%$ & $5.02 \%$ & $5.00 \%$ & $63.60 \%$ \\
\hline AGV5 & 119 & $38.64 \%$ & $9.40 \%$ & $10.33 \%$ & $32.14 \%$ & $4.75 \%$ & $4.74 \%$ & $61.36 \%$ \\
\hline average & $661($ total $)$ & $33.49 \%$ & $8.66 \%$ & $11.60 \%$ & $35.67 \%$ & $5.30 \%$ & $5.28 \%$ & $66.51 \%$ \\
\hline \multicolumn{9}{|c|}{ Program4:6 AGVs } \\
\hline Item & $\begin{array}{l}\text { The number of } \\
\text { execution }\end{array}$ & The idle rate & $\begin{array}{l}\text { The charging } \\
\text { time }\end{array}$ & $\begin{array}{l}\text { The unloading } \\
\text { walking time }\end{array}$ & $\begin{array}{l}\text { The loading } \\
\text { walking time }\end{array}$ & $\begin{array}{l}\text { The loading } \\
\text { time }\end{array}$ & $\begin{array}{l}\text { The unloading } \\
\text { time }\end{array}$ & $\begin{array}{l}\text { The total } \\
\text { load rate }\end{array}$ \\
\hline AGV1 & 128 & $34.70 \%$ & $8.94 \%$ & $11.72 \%$ & $34.31 \%$ & $5.16 \%$ & $5.16 \%$ & $65.30 \%$ \\
\hline AGV2 & 119 & $35.76 \%$ & $9.83 \%$ & $12.11 \%$ & $32.72 \%$ & $4.80 \%$ & $4.78 \%$ & $64.24 \%$ \\
\hline AGV3 & 114.5 & $38.15 \%$ & $10.29 \%$ & $11.33 \%$ & $31.01 \%$ & $4.62 \%$ & $4.60 \%$ & $61.85 \%$ \\
\hline AGV4 & 108.5 & $40.60 \%$ & $10.69 \%$ & $10.29 \%$ & $29.65 \%$ & $4.39 \%$ & $4.38 \%$ & $59.40 \%$ \\
\hline AGV5 & 98 & $42.25 \%$ & $10.14 \%$ & $13.21 \%$ & $26.50 \%$ & $3.95 \%$ & $3.95 \%$ & $57.75 \%$ \\
\hline AGV6 & 104 & $44.61 \%$ & $8.45 \%$ & $10.66 \%$ & $27.91 \%$ & $4.20 \%$ & $4.17 \%$ & $55.39 \%$ \\
\hline average & 672 (total) & $39.34 \%$ & $9.72 \%$ & $11.55 \%$ & $30.35 \%$ & $4.52 \%$ & $4.51 \%$ & $60.66 \%$ \\
\hline
\end{tabular}

\section{The Analysis of the Results}

The simulation result of the AS/RS: the average utilization rate of the stacker is $71.82 \%$, the average utilization rate of the shuttle is $68.18 \%$. This result is corresponded with the need of the real production and also has a certain margin.

The simulation result of the AGV system is shown in the table 1.In order to determine the best number of the AGV in this automatic accessories distribution system, we especially take four cases of 3,4,5,6 AGVs to simulate each operation status. In the case of $3 \mathrm{AGVs}$, the utilization rate can be over $90 \%$. In that case, the AGV part can easily becomes the bottleneck of this system though it can be made the full use of. And we can also tell from the simulation data that in the normal working conditions, these $3 \mathrm{AGVs}$ can just meet the requirements, but once the peak appears, they can hardly meet the requirements. On the contrary, in the case of 6 AGVs, the margin is much larger than the actual needs. We can easily tell from the simulation data that in the case of 4 AGVs, the maximum of the response time is only 13.17 minutes, which is less than the requirement of 15 minutes, so 4 AGVs are able to fully meet the working requirement. And considering of keeping balance of the ability of the whole system, we can finally determine that the configuration of 4 AGVs is the ideal program.

\section{CONCLUSION}

Based on the real production needs, through researching the general principles of the multi-tasks scheduling and controlling simulation in the logistics center, focusing on the AGV system, this paper set up the simulation models of the equipments and established the relationships between them. Finally we got the visualized models of the accessories distribution system of one cigarettes logistics center, and studied the simulation method of the multi-tasks scheduling and controlling in the logistics center.

The simulation method of the multi-tasks scheduling and controlling in the logistics center which is deliberated by this paper is impressively innovative. This article opened up a new researching direction of the simulation modeling technology, and paved the way to the further studies and improvements of the intelligent simulation modeling technologies in the logistics center. 


\section{ACKNOWLEDGMENT}

F. A. Author is thankful to professor Cheng, who is also the S.B. Author. He enlightened me with his innovative ideas and spirit. Author is also grateful to her parents for supporting and encouraging her for achieving her goals.

\section{REFERENCES}

[1] R. Muther, Systematic Layout Planning, Kansas U.S.A: Industrial Education Institute, May, 1969

[2] A. Verbraeck and E. Valentin, "Simulation as a real time logistic control system: AGV control with simple ++," in Proc. the 2003 Winter Simulation Conference, 2003

[3] Z. Chenbeixi etc., "The review of the development of the automatic guided vehicle (AGV)," Manufacture Information Engineering of China, January 2010.

[4] W. Yong etc., "Technical Analysis of the AGV system," China Science and Technology Information, April 2011.

[5] X. Haining, "Real-time multi-attribute dispatching method for automatic guided vehicle system," Computer integrated manufacturing system, October 2012.

[6] B. Shuaifu etc., "Research of Multiple AGV Systems Based on Mixed Regional Control Module," Mechanical and electron, March 2012.

[7] H. Kewei, Study on Navigation and Obstacle Avoidance Technique for Auto Guided Vehicle (AGV) Ms D Thesis, Zhejiang: Zhejiang University, 2012
[8] X. Tianran etc., "Research of the flexible manufacturing systems layout based on simulation," Machine building \& automation, May 2006.

[9] Z. Xiaojiao etc., "Shallow discussion Just-In-Time (JIT) production mode," Guide to Business, 2012

[10] X. Du, "Development of flexible manufacturing system (FMS)," Science \& Technology Association Forum, 2010

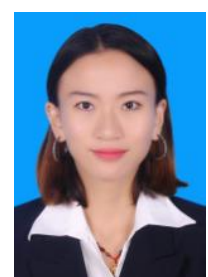

Zhao Wenjing was born in 1989. Ms. ZHAO received her Bachelor degree in Industria Engineering in 2007, currently she is studying Logistics Engineering at the University of Science and Technology Beijing, aiming at the layout planning in the logistics center.

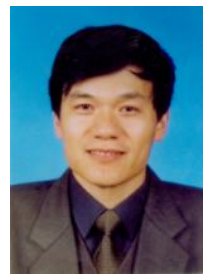

Cheng Guoquan was born in 1960 . He received his master degree in mechanical engineering in 1984. Now he is the associate professor at the Institute of Logistics Engineering, University of Science and Technology Beijing. Professor Cheng has published many influential books and papers in China. His research specialty is the layout planning in the logistics center and the logistics park. 